\title{
ASSISTÊNCIA À POPULAÇÃO EM SITUAÇÃO DE RUA DURANTE A PANDEMIA: O PROGRAMA CONSULTÓRIO NA RUA
}

\author{
Kenny Paolo Ramponi' \\ ORCID: 0000-0001-7464-806X \\ José Levi de Jesus Pereira" \\ ORCID: 0000-0002-8557-194X \\ Maria Delmira Melo" \\ ORCID: 0000-0002-2769-5514
}

Ana Stella de Azevedo Silveira' ORCID: 0000-0003-3630-5001

\begin{abstract}
'Departamento Científico de Enfermagem Psiquiátrica e Saúde Mental, da Associação Brasileira de Enfermagem - Seção São Paulo. São Paulo, São Paulo, Brasil.

"Centro Social Nossa Senhora do Bom Parto. São Paulo, São Paulo, Brasil.
\end{abstract}

Autor Correspondente:

Kenny Paolo Ramponi E-mail:kprig@hotmail.com

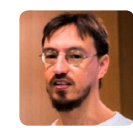

Como citar:

Ramponi KP, Pereira JLJ, Melo MD, Silveira ASA. Assistência à população em situação de rua durante a pandemia: o programa consultório na rua. In: Esperidião E, Saidel MGB (Orgs.). Enfermagem em saúde mental e COVID-19. 2.ed.rev. Brasília, DF: Editora ABEn; 2020. p. 51-55. (Série Enfermagem e Pandemias, 4). https://doi.org/10.51234/aben.20.e04.c07

\section{INTRODUÇÃO}

Em 11 de março de 2020, a Organização Mundial da Saúde (OMS) anunciou que o surto da COVID-19, doença causada pelo novo coronavírus SARS-CoV-2, havia se espalhado pelo mundo de tal modo a caracterizar uma pandemia ${ }^{(1)}$. Esse cenário exigiu uma importante reorganização nas práticas em saúde dos países afetados, de modo a buscar um equilíbrio entre proteger a saúde, minimizar as perdas econômicas e sociais e respeitar os direitos humanos ${ }^{(1,2)}$.

A COVID-19 é caracterizada por um quadro clínico que varia de infecções assintomáticas a quadros respiratórios graves com alta transmissibilidade ${ }^{(3,4,5,6)}$. No Brasil, o primeiro caso foi oficialmente notificado em 26 de fevereiro de 2020 no Município de São Paulo (MSP)(4), fazendo com que as diversas esferas que compõem o Sistema Único de Saúde (SUS), se organizassem para atender a demanda gerada por um vírus de impacto sem precedentes ${ }^{(5)}$. Passados quatro meses da chegada da doença ao país, contavam-se mais de um milhão de pessoas contaminadas pela COVID-19, com o total de óbitos ultrapassando $57.000^{(7)}$.

Os protocolos sanitários ${ }^{(4,6)}$ para a prevenção da COVID-19 orientam a lavagem frequente das mãos com água e sabão, o uso do álcool em gel, o não compartilhamento de objetos pessoais, o uso da máscara de proteção facial e o distanciamento social. Essas orientações foram amplamente veiculadas através de diversas campanhas e mobilizações. Em março, os estabelecimentos do MSP começaram a seguir novas diretrizes e aqueles considerados não essenciais tiveram suas atividades interrompidas a fim de reduzir a circulação do vírus( ${ }^{(8)}$.

Nesse sentido, as barreiras determinadas para proteger as pessoas contra a COVID-19 foram as mesmas que criaram limitações para o cuidado de populações mais vulneráveis, como aquela em situação de rua. Seguir os protocolos sanitários estabelecidos pode ser um grande desafio para essa população que carece de insumos básicos de higiene 
e até mesmo de acesso à água tratada. Já a diminuição de circulação de pessoas nas ruas e o fechamento de estabelecimentos comerciais prejudicam ainda mais a situação financeira da Pessoa em Situação de Rua (PSR), aumentando sua vulnerabilidade.

O MSP soma 24.344 pessoas vivendo em situação de rua ${ }^{(9)}$, gerando grande impacto sobre seus indicadores de saúde. O Programa Consultório na Rua (CnaR), foi instituído pela Política Nacional de Atenção Básica, em 2011, e visa ampliar o acesso dessa população aos serviços de saúde, oferecendo-lhes atenção integral ${ }^{(10,11)}$. A equipe multiprofissional do CnaR atua primordialmente extramuros e utiliza da criação de vínculos no território como principal ferramenta de acesso aos pacientes. Com nove anos de experiência acumulada, o CnaR mostra grande potencial para assistir as condições de saúde dessa população, agora agravadas pela situação da pandemia ${ }^{(10)}$.

A partir dos princípios norteadores do SUS de universalização, equidade e integralidade ${ }^{(12)}$, o presente artigo propõe refletir sobre a atuação do CnaR para a promoção e ampliação do acesso à assistência à saúde da PSR em tempos de pandemia.

\section{OBJETIVO}

Refletir sobre a contribuição do CnaR no MSP para a garantia dos princípios preconizados pelo SUS na assistência à PSR durante o período de pandemia da COVID-19.

\section{MÉTODO}

Trata-se de um estudo de reflexão fundamentado na literatura nacional e internacional. Os resultados observados foram discutidos a partir dos princípios fundamentais do SUS de universalização, equidade e integralidade ${ }^{(12)}$.

\section{RESULTADOS E DISCUSSÕES}

\section{Universalização}

De acordo com o princípio da universalização, a saúde é um direito que deve ser assegurado pelo Estado a todas as pessoas, independentemente de características sociais ou pessoais ${ }^{(12)}$.

Tradicionalmente, a PSR tem seus direitos violados, incluindo o direito de acessar os serviços de saúde, comprometendo o seu autocuidado e contribuindo para perpetuar a condição de exclusão e marginalização ${ }^{(13)}$. O CnaR facilita o acesso à saúde deste grupo social, historicamente excluído e estigmatizado, garantindo assim o princípio da universalização.

A partir do momento em que o MSP foi afetado pela pandemia da COVID-19, foi observada uma mudança importante no padrão das ações realizadas pelo CnaR. Algumas ações tiveram que ser reduzidas e/ou adaptadas devido às restrições impostas através de decretos estaduais e municipais para prevenção da COVID-19 enquanto outras ações foram intensificadas para realizar a sensibilização da PSR.

No contexto da pandemia, mais uma vez o CnaR do MSP mostrou comprometimento com o princípio da universalização, ao rapidamente desenvolver estratégias que contemplassem as novas demandas. Para garantir o acesso à saúde foi necessária uma reorganização das atividades ofertadas à PSR pelo CnaR, incluindo aumento de ações ligadas a Enfermagem como: busca ativa de pessoas sintomáticas, aferição de oximetria, temperatura e pressão arterial e avaliação da presença de tosse e outros sinais e sintomas característicos da COVID-19.

Em se tratando de uma doença altamente contagiosa, acesso à informação é sinônimo de acesso à saúde. Desse modo, houve uma intensa implicação das equipes na divulgação de informação sobre as principais medidas de prevenção contra o coronavírus. Materiais de higiene, água, álcool em gel e máscaras de pano passaram as ser distribuídas para essa população. Paralelamente, houve a aplicação da vacina contra o vírus da influenza. 
Entre as ações promovidas pelo poder público municipal para o enfrentamento da COVID-19 neste período, destacamos a criação de Centros de Acolhida emergenciais específicos para o encaminhamento da PSR com suspeita ou diagnóstico confirmado pela COVID-19, a fim de facilitar o distanciamento e isolamento social por até 14 dias. Além disso, pessoas com a doença confirmada ou quadros agravados foram direcionados aos Hospitais de Campanha ${ }^{(14)}$.

\section{Equidade}

O princípio de equidade ${ }^{(12)}$ tem como objetivo diminuir desigualdades e é valioso para uma população que por muito tempo contava com os serviços de urgência e emergência como única possibilidade de cuidado ${ }^{(12)}$.

A equidade preconizada pelo SUS é concretizada no cotidiano de trabalho do CnaR, no qual há um planejamento diário e dinâmico que visa suprir as diversas demandas do território.

Uma das formas de operar a equidade em tempos de pandemia foi intensificar o trabalho já exercido pelo CnaR, ampliando o cuidado para a PSR, uma vez que equidade "significa tratar desigualmente os desiguais, investindo mais onde a carência é maior"(12). Exemplo disso é que alguns atendimentos e procedimentos considerados eletivos para a população em geral foram suspensos ou adaptados, enquanto o CnaR do MSP teve seu horário de funcionamento estendido, suas equipes aumentadas e seus dias de funcionamento ampliados para os finais de semana.

\section{Integralidade}

O princípio da integralidade considera as pessoas como um todo e preza pela integração de ações de promoção da saúde, prevenção de doenças, tratamento e reabilitação ${ }^{(12)}$.

A multiprofissionalidade do CnaR permite que uma equipe consiga suprir as diferentes demandas da PSR. No MSP, essa equipe é composta por Médico Generalista, Enfermeiro, Assistente Social, Psicólogo, Auxiliar de enfermagem, Agente Social, Agente de Saúde de Rua, Auxiliar Técnico Administrativo e Dentista. As equipes do município contam com um diferencial; seus Agentes de Saúde de Rua são captados, principalmente, dos Centros de Acolhida, ou seja, eles próprios vivenciaram ou vivenciam a situação de rua. Além de facilitar a identificação com a população em questão, essa vivência proporciona acesso digno ao mercado formal de trabalho.

Ainda em consonância com o princípio da integralidade, destacamos as articulações com os diversos serviços de saúde e serviços intersetoriais no território que foram fortalecidas devido ao agravo da COVID-19, com uma participação ativa dos serviços e equipes do Sistema Único da Assistência Social (SUAS), como os Centros de Acolhida, a equipe do Serviço Especializado de Abordagem Social (SEAS), os Centro de Referência da População em Situação de Rua (CentroPop) e os Centro de Referência Especializados de Assistência Social (CREAS).

Em razão da pandemia, as parcerias já existentes com outros serviços de saúde como Unidades Básicas de Saúde (UBS) e o Centro de Atenção Psicossocial (CAPS) foram ampliadas através de estratégias como discussão de casos e grupos de trabalho.

Outras ações das iniciativas pública e privada para enfrentar a pandemia de modo integral incluíram a instalação de tendas com chuveiros, tanques e máquinas para lavar roupa e pias para lavagem das mãos em diversos pontos da cidade.

\section{CONSIDERAÇÕES FINAIS}

Na história das calamidades e catástrofes ligadas à saúde pública, é frequente que haja aumento da vulnerabilidade e do estigma e discriminação contra grupos específicos de pessoas afetadas ${ }^{(1)}$. A garantia de acesso à assistência à saúde e demais políticas sociais pela PSR nesse momento deve ser entendida, em primeiro lugar, como direito de cidadania. 
As estratégias descritas nessa reflexão revelam o CnaR como um serviço essencial no cuidado da PSR em tempos de pandemia, alinhado com os princípios do SUS de universalização, equidade e integralidade. A participação popular, um dos princípios organizativos do SUS, faz-se essencial a fim de garantir que as conquistas adquiridas nesse momento possam se consolidar como políticas públicas permanentes. A reflexão contribui também para pensar e exaltar a função dos profissionais de saúde e das políticas públicas acerca da prevenção da COVID-19 para a PSR.

Destaca-se como obstáculo para o CnaR sensibilizar uma população extremamente vulnerável, através de um trabalho contínuo que se dá com afeto e vínculo, ainda que respeitando as medidas de prevenção necessárias. O desafio é diário e as experiências devem ser compartilhadas, pois, aprender e inovar é fundamental nesse período.

\section{AGRADECIMENTOS}

Ao Departamento de Enfermagem Psiquiátrica e Saúde Mental/Associação Brasileira de Enfermagem (DEPSM/ABEn) e ao Centro Social Nossa Senhora do Bom Parto.

\section{REFERÊNCIAS}

1. Word Health Organization. OMS afirma que COVID-19 é agora caracterizada como pandemia.[internet]. 202011 mar.[citado 25jun 2020]. Disponível em: https://www.paho.org/bra/index.php?option=com_ content\&view=article\&id=6120:oms-afirma-que-covid-19-e-agora-caracterizada-como-pandemia\&ltemid=812.

2. Word Health Organization. Abordagem de Direitos Humanos, essencial na resposta à COVID-19 [internet]. 2020 [citado 22 jun 2020]. Disponível em: https://iris.paho.org/handle/10665.2/52369.

3. Johns Hopkins University \& Medicine. CORONAVIRUS RESOURCE CENTER.[internet]. 2020 [citado 25 jun 2020]. Disponível :https://coronavirus.jhu.edu/map.html

4. Secretaria Estadual da Saúde São Paulo. Orientações e Notas Técnicas.[internet].2020 [citado28 jun 2020].Disponível em:http://www.saude.sp.gov.br/cve-centro-de-vigilancia-epidemiologica-prof.-alexandre-vranjac/areas-de-vigilancia/ doencas-de-transmissao-respiratoria/coronavirus-covid-19/orientacoesnotas-tecnicas

5. Brasil. Ministério da Saúde. Sobre a doença. 2020.[internet] 2020. [citado 25 jun 2020] Disponível em: <https://coronavirus. saude.gov.br/sobre-a-doenca\#o-que-e-covid

6. Word Health Organization. Folha Informativa - COVID-19.[internet]2020[citado29 jun 2020]Disponível em: https://www. paho.org/bra/index.php?option=com_content\&view=article\&id=6101:covid19\&ltemid=875

7. Brasil. Ministério da Saúde. Boletim Epidemiológico COVID-19 número 20. [internet] 2020. [citado 21 jun 2020] Disponível em: http://saude.gov.br/images/pdf/2020/July/01/Boletim-epidemiologico-COVID-20-3.pdf

8. Brasil. Diário Oficial da União. Decreto n 10.329, de 28/04/20 DOU de 29/04/20 p. 5 - seção 1 n 81 - Altera o Decreto n० 10.282, de 20 de março de 2020, que regulamenta a Lei n 13.979, de 6 de fevereiro de 2020, para definir os serviços públicos e as atividades essenciais. 2020, mar.20; Secção1. p 1.

9. Prefeitura de São Paulo. Secretaria Especial de Comunicação. Prefeitura de São Paulo divulga Censo da População em Situação de Rua 2019: [internet] 202031 jan. [citado 28 jun 2020]. Disponível em:http://www.capital.sp.gov.br/noticia/ prefeitura-de-sao-paulo-divulga-censo-da-populacao-em-situacao-de-rua-2019

10. Brasil. Ministério da Saúde. Secretaria de Atenção Primária à Saúde Consultório na Rua. [internet]. [citado 22 jun 2020] Disponível em: https://aps.saude.gov.br/ape/consultoriorua/\#: :text=A\%20estrat\%C3\%A9gia\%20Consult\%C3\%B3rio\%20 na\%20Rua,encontra\%20em\%20condi\%C3\%A7\%C3\%B5es\%20de\%20vulnerabilidade.

11. Brasil. Ministério da Saúde. Portaria no 122, de 25 de Janeiro de 2011. Define as diretrizes de organização e funcionamento das Equipes de Consultório na Rua.

12. Brasil. Ministério da Saúde. Princípios do SUS.[internet] [citado 29 jun 2020]. Disponível em: https://www.saude.gov.br/ sistema-unico-de-saude/principios-do-sus 
13. Pereira JLJ, Peixoto RAO. A população em situação de rua e o acesso ao sus: um estudo sobre a experiência do programa consultório na rua no Município de São Paulo Monografia. São Paulo: Universidade Nove de Julho; 2017.

14. BRASIL. Agência Nacional de Vigilância Sanitária. [internet] 202009 abr. [citado 01 jul 2020]. Disponível em: http://portal.anvisa.gov.br/noticias//asset_publisher/FXrpx9qY7FbU/content/ conheca-as-orientacoes-para-hospitais-de-campanha/219201 